\title{
PERSPECTIVAS FUTURAS E IMPACTO SOCIAL DE LAS BIOTECNOLOGÍAS VEGETALES
}

\section{OUTLOOK AND SOCIAL IMPACT OF PLANT BIOTECHNOLOGIES}

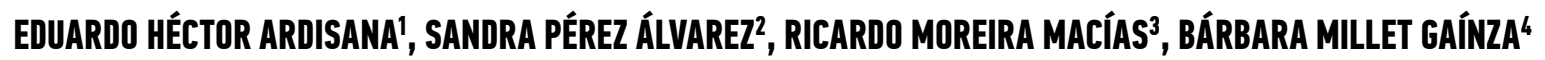

1 Escuela Superior Politécnica de Chimborazo, Ecuador. ehectorardisana@gmail.com

2 Instituto Politécnico Nacional, CIIDIR-IPN, México. perezalvarezsandra2015@gmail.com

3 Universidad Católica de Santiago de Guayaquil, Ecuador. ricardo.moreira@iniap.gob.ec

4 Universidad Agraria de La Habana, Cuba. barbaramilletgainza@gmail.com

RESUMEN

Las investigaciones en biotecnología vegetal han conducido a la introducción en la agricultura de numerosos productos científicos, entre los que se destacan el mejoramiento genético y la multiplicación acelerada de especies vegetales, la conservación de germoplasma y las plantas transgénicas. Al mismo tiempo, se ha mantenido un constante debate sobre los beneficios y costos sociales de las aplicaciones biotecnológicas, principalmente dirigido hacia la inserción de los organismos genéticamente modificados en la agricultura. Este artículo tiene como objetivo hacer un balance de las perspectivas actuales y futuras de la aplicación de las biotecnologías vegetales en la agricultura, y de las implicaciones de su empleo para la sociedad. Se discuten los resultados más recientes obtenidos en esta área del conocimiento. Se concluye que la biotecnología vegetal ha demostrado su valor científico y aplicación práctica, aunque subsisten desigualdades en la propiedad sobre los avances y las ganancias obtenidas, las cuales tienden a mantenerse en el futuro.

PALABRAS CLAVE: biotecnología vegetal, cultivo de tejidos, conservación de germoplasma, transgénesis.
ABSTRACT

Research in plant biotechnology has led to the introduction of numerous scientific agriculture products, among which breeding and rapid multiplication of plant species, conservation of germplasm and transgenic plants are included. At the same time, it has remained a constant debate about the benefits and social costs of biotechnological applications, mainly directed towards the insertion of genetically modified organisms in agriculture. This article aims to take stock of current and future perspectives on application of plant biotechnologies in agriculture and their implications of use to society. The most recent results in this area of knowledge are discussed. It is concluded that plant biotechnology has demonstrated its scientific value and practical application, although there are still inequalities in the ownership of progress and profit obtained, which tend to remain in the future.

KEYWORDS: plant biotechnology, tissue culture, germplasm preservation, transgenesis. 


\section{INTRODUCCIÓN}

Desde los primeros éxitos en el cultivo in vitro de especies vegetales alcanzados por Gottlieb Haberlandt en 1902 hasta la actualidad, un largo camino se ha recorrido en esta área del conocimiento. Los estudios de laboratorio han conducido a la introducción de variadas tecnologías en la producción agrícola, entre las que se destacan el mejoramiento genético y la multiplicación acelerada de especies de plantas, el rescate y conservación de germoplasma y la modificación del genoma vegetal (GarcíaGonzáles, Quiroz, Carrasco \& Caligari, 2010).

Un dato que ilustra el presente nivel de introducción de las biotecnologías en la agricultura es, sin duda, el incremento dramático del área mundial sembrada con cultivos transgénicos, que pasó de 0 a 181,5 millones de hectáreas entre 1996 y 2014, a un ritmo sostenido de crecimiento entre 3 y $4 \%$ (James, 2014). Sin embargo, estas cifras se refieren sólo a una de las biotecnologías de más reciente introducción y por cierto a la que más polémica desata en los medios: la transgénesis. Sobre otros procedimientos biotecnológicos como la micropropagación de plantas, el uso de la variación somaclonal y la selección in vitro en el mejoramiento, la conservación in vitro de germoplasma y el empleo de biorreactores de células vegetales, a pesar de haberse estudiado tanto o más que la transgénesis, es mucho más difícil obtener datos globales.

A más de 50 años del inicio de la aplicación de la biotecnología en la agricultura, se mantiene la discusión acerca de sus beneficios y costos sociales. El blanco principal de las acusaciones ha sido la transgénesis, por el alcance de sus posibles impactos en el medio ambiente y la sociedad (Altieri, 2003). Otras tecnologías más "blandas" han sufrido menores críticas. Este artículo se propone hacer un balance de las perspectivas actuales y futuras de aplicación de las biotecnologías vegetales en la agricultura, y de las implicaciones de su empleo para la sociedad.

CONSERVACIÓN DE GERMOPLASMA POR MÉTODOS BIOTECNOLÓGICOS

Los recursos fitogenéticos son de cardinal importancia para la humanidad, pues constituyen la fuente para el mejoramiento genético y la obtención de nuevas variedades de especies vegetales. Sin embargo, la actividad antrópica ha causado un impacto negativo que ha conducido a una disminución importante del germoplasma silvestre. Como señalan Sarasan, Cripps, Ramsay, Atherton, McMichen, Prendergast \& Rowntree
(2006), en el período de 1996 a 2004, la alarmante cantidad de 8321 especies de plantas engrosó la lista roja de especies amenazadas de la Unión Internacional para la conservación de la naturaleza y los recursos naturales. Se estima que esta cifra se incrementa cada año en proporciones no siempre calculables. Aunque autores como Rao (2004) señalan la pérdida anual de más de 15 millones de hectáreas de bosque tropical, es difícil apreciar cuántas especies (incluso aún desconocidas para el hombre) desaparecen con ellas. La conservación del germoplasma es, pues, una tarea primordial.

Existen dos formas de conservar el germoplasma: in situ (en el centro de origen de la especie) y ex situ (en colecciones situadas fuera de éste). Ambas tienen en común los riesgos de exposición de las plantas a plagas, enfermedades, catástrofes naturales y vandalismo (Noor, Kean, Vu \& Mohammed-Hussein, 2011) que pueden causar su desaparición. Como una alternativa se ha desarrollado la conservación in vitro, expresión particular de las colecciones ex situ. Las técnicas in vitro son útiles para conservar la biodiversidad vegetal, incluyendo recursos genéticos con semillas recalcitrantes, especies que se propagan vegetativamente, especies raras y amenazadas y productos del propio mejoramiento biotecnológico, como genotipos élite y organismos genéticamente modificados (Engelmann, 2011).

Dos variantes fundamentales se han desarrollado para preservar el germoplasma en condiciones seguras. La primera es la conservación en medios de cultivo que retardan el crecimiento. Esto se logra a través de la reducción de la temperatura y la intensidad luminosa, y la adición de agentes osmóticos o retardadores del crecimiento (Noor et al., 2011). La segunda es la crioconservación, en la cual los tejidos o embriones se mantienen a muy bajas temperaturas en nitrógeno líquido. Una vez descongelados, los embriones o tejidos pueden recuperarse y cultivarse en medios que contengan los nutrientes necesarios para su desarrollo (Pence, 2011).

A la hora de determinar si es necesaria y recomendable la utilización de técnicas in vitro para la preservación de una especie vegetal amenazada, se debe tomar en cuenta un conjunto de elementos. En primer lugar, si es posible su reproducción a través de semillas o partes vegetativas como yemas, estacas, estolones o rizomas. En casos como estos, se debe recurrir a la forma más simple de preservación, para minimizar los costos de investigación. Cuando 
se trata de plantas que no producen semillas, o con semillas recalcitrantes, la preservación in vitro a corto y mediano plazo, y la crioconservación a largo plazo parecen ser las alternativas más promisorias (Pence, 2011), ver la Figura 1 tomada del propio Pence (2011).

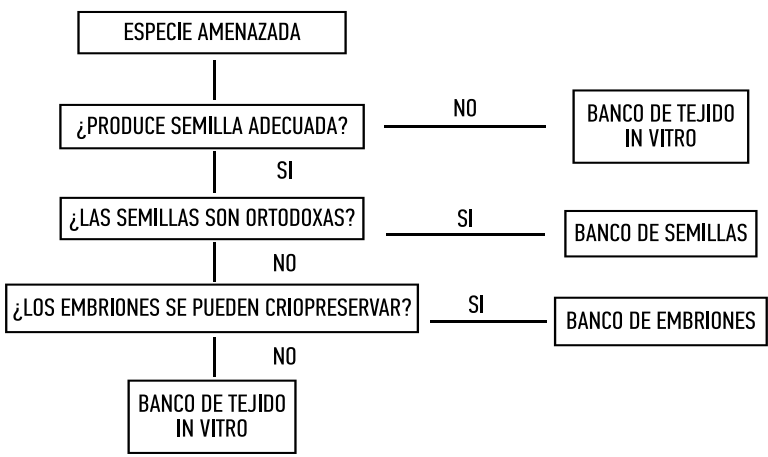

Figura 1. Identificación de métodos a emplear para la conservación de especies amenazadas

MULTIPLICACIÓN MASIVA DE PLANTAS Y MEJORAMIENTO GENÉTICO IN VITRO

Desde los inicios del cultivo de tejidos vegetales, una de sus principales aplicaciones potenciales fue la multiplicación acelerada de plantas. Las posibilidades que brindan el rápido crecimiento de los tejidos cultivados in vitro y la obtención de nuevos brotes en cortos períodos de tiempo hicieron ver como muy promisoria esta línea de trabajo. Como señalan García-Gonzáles etal. (2010), si se considera un genotipo con una tasa de multiplicación de tres semanas, un ciclo de propagación de cuatro semanas y una pérdida del $10 \%$ del material por contaminación o errores de manipulación, alrededor de un millón de plantas se obtendrían en sólo doce meses, partiendo de un solo explante.

Esta perspectiva condujo a que en muchos países surgieran laboratorios dedicados exclusivamente a la micropropagación de plantas. En Cuba, por ejemplo, se desarrolló un concepto superior, el de "biofábricas" (Pérez, 1998), grandes empresas que además de las labores del cultivo de tejidos per se, incluían áreas de aclimatación, laboratorios para la detección de virus y su control por termoterapia, y otras facilidades. En ese país, una parte significativa de la semilla certificada de caña de azúcar, plátanos, papa y otras especies llegó a producirse por vías biotecnológicas en las décadas de 1980-1990. En años recientes se han obtenido avances en el mundo en la propagación de numerosas especies, tales como diversos tipos de hortalizas (Estopá, 2005), plantas medicinales como Stemona tuberosa Lour (Biswas, Bari, Roy \& Bhadra, 2011), la pal- ma datilera Phoenix dactylifera L. (Adel Ahmed \& Shaimaa Mohamed, 2010) y nuevos cultivares de Musa sp. (Rahman, Biswas, Mehedi Hassan, Golam Ahmed, Mamun, Rafiqul Islam, ... \& Enamul Haque,2013), entre otras.

Los esfuerzos actuales en la investigación se están dedicando a poner a punto tecnologías más complejas, que buscan reducir aún más el espacio dedicado a la multiplicación masiva, mediante el empleo de sistemas de inmersión temporal y biorreactores que se basan en el aprovechamiento de la embriogénesis somática (Ducos, Terrier \& Courtois, 2009). Estos equipos tienen además como ventajas la posibilidad de propagar las plantas en escalas aún mayores que la micropropagación convencional, y de servir como biorreactores para obtener metabolitos útiles a las industrias química, alimentaria y farmacéutica.

A partir de la producción de embriones somáticos viables en sistemas de inmersión temporal, una nueva tecnología comienza a aparecer en el panorama de la multiplicación masiva de plantas: la semilla artificial. Se trata de recubrir estos embriones con una película nutritiva y protectora, que cumpla las funciones del endospermo en la semilla gámica. Estos embriones encapsulados podrían utilizarse como material de propagación con ventajas sobre las vitroplántulas, relativas al área ocupada por los propágulos, las posibilidades de almacenamiento y el potencial que ofrecen para la multiplicación de especies que no producen semillas convencionales. Aunque se han obtenido resultados promisorios en algunas especies (Asmah, Hasnida, Nashatul Zaimah, Noraliza \& Nadiah Salmi, 2011); Bekheet, 2006; Vdovitchenko \& Kuzovkina, 2011) persisten problemas en la viabilidad, la sincronización y la susceptibilidad a la desecación de los embriones somáticos, lo que hacen de esta tecnología una herramienta prometedora pero de limitada aplicación en la actualidad.

Pronto se observó que una parte de las plantas obtenidas por cultivo in vitro mostraba ciertos niveles de variación, la cual fue denominada variación somaclonal (Larkin \& Scowcroft, 1981). Varios son los factores que causan la variación somaclonal, como el tipo de explante, el crecimiento desorganizado de las células meristemáticas, el genotipo de las células en cultivo, su nivel de ploidía, el patrón de metilación del ADN, y la composición del medio de cultivo, en particular la concentración de reguladores de crecimiento (Aversano, Savarese, De 
Nova, Frusciante, Punzo \& Carputo, 2009). No obstante, la explicación del porqué un genotipo vegetal puede dar lugar a diferentes fenotipos bajo similares condiciones de cultivo aún no está clara, y hoy se atribuye más a la regulación epigenética que a mutaciones del ADN (Miguel \& Marum, 2011).

En cualquier caso, la aparición de variaciones en las plantas obtenidas in vitro, si bien es un obstáculo a la micropropagación de muchas especies, abrió el camino al mejoramiento genético por cultivo de tejidos, principalmente orientado hacia la eliminación o reducción de la expresión de caracteres indeseables. Su explotación ha conducido al desarrollo de nuevos cultivares con mejoras en el rendimiento, la madurez temprana y la resistencia al estrés biótico y abiótico (Jain, 2001).

No obstante, el carácter aleatorio de la variación somaclonal hace prácticamente imposible direccionar el mejoramiento in vitro cuando se hace únicamente a través de esta vía. Aunque en algunas especies se sigue empleando la variación somaclonal (Karim, Ahmed, Krishna Roy, Ara, Islam \& Hossain ,2015), se han desarrollado otras técnicas encaminadas a seleccionar las células, tejidos o plantas de interés en el propio frasco de cultivo, enfrentándolas a metabolitos tóxicos que causen la muerte de las células susceptibles y permitan el normal crecimiento de las resistentes. Estas técnicas se agrupan bajo el nombre de selección in vitro, y funcionan según un esquema general que se muestra en la Figura 2.

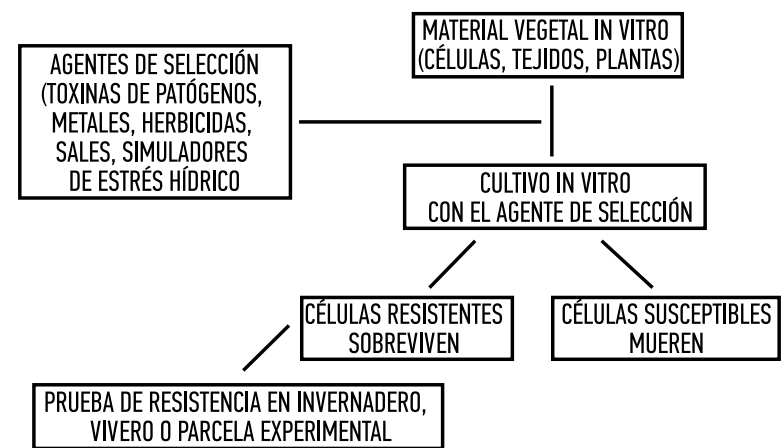

Figura 2. Esquema general de selección in vitro en tejidos vegetales

La versatilidad de estas técnicas permite su aplicación en la obtención de material potencialmente resistente a hongos patógenos $(\mathrm{Ru}-$ gini, Gutiérrez-Pesce, Silvestri, Lamancusa, Chiavaioli, Vittori \& De Pace, 2014); Valencia, Pascual y Delfín, 2014), metales pesados (Priyadarsini, Sahoo \& Rout, 2015), tolerancia a la sal (Khorami \& Safarnejad, 2011) y a la sequía
(Mahmood, Razzaq, Rasheed, Qayyum \& Ahmad, 2014) y su combinación con la mutagénesis (Koch, Ramgareeb, Stuart, Snyman \& Watt, 2012). Empero, tienen una importante debilidad: no todos los caracteres deseables que se expresan in vivo lo hacen también en las células, tejidos y plantas cultivados in vitro.

\section{PLANTAS TRANSGÉNICAS}

El fitomejoramiento a menudo demora décadas y frecuentemente se obtienen variedades con características imprevistas y no deseadas. Es aleatorio y lento, limitado por la disponibilidad de rasgos deseables en especies de plantas estrechamente relacionadas. El mejoramiento in vitro a través de variación somaclonal, mutaciones y selección in vitro tampoco ha sido una solución totalmente efectiva. En cambio, la ingeniería genética permite reducir la incertidumbre y el tiempo, transfiriendo rasgos de plantas más alejadas filogenéticamente (Barrows, Sexton \& Zilberman, 2014). Desde el desarrollo de estas plantas mediante la tecnología de ADN recombinante, los cultivos han adquirido características que no hubiesen tenido mediante el mejoramiento convencional (Andrioli, 2013; Ribeiro \& Marín, 2012).

A través de la biotecnología moderna, ha sido posible avanzar en la agricultura con nuevos descubrimientos en el mejoramiento de las plantas. Así, cultivos tradicionales están siendo reemplazados por cultivares mejorados y plantas transgénicas, para incrementar la productividad de los cultivos y de esta forma satisfacer la demanda de alimentos (Silva \& Leite, 2013).

El primer alimento genéticamente modificado autorizado para consumo humano fue el tomate Flav Savr, en 1994. Este tomate se estropeaba más lentamente que el convencional, lo que permitía a los agricultores recolectar los frutos cuando estaban maduros, en lugar de alcanzar la madurez, como los tomates convencionales. Sin embargo, resultó ser un fracaso comercial (Weasel, 2008).

En algunos casos se pueden insertar genes para que sinteticen una mayor cantidad de nutrientes o nutrientes nuevos. Un ejemplo es el denominado arroz dorado, que sintetiza moléculas precursoras de la vitamina $\mathrm{A}$ y que se propone como complemento en lugares donde la dieta es pobre en esta vitamina (Paine, Shipton, Chaggar, Howells, Kennedy, Vernon, ... \& Drake, 2005). 
Qaim (2009) resumió estudios de impactos referidos al algodón Bt (resistente a insectos) en regiones de la India, encontrando un aumento en la productividad de 37, 33 y $24 \%$ debido al mejoramiento de ese carácter. Los estimados de producción en el mundo desarrollado son menores, con la producción de los EUA aumentando solo en un 10\%. Un resultado similar se encontró en el maíz Bt con un estimado de aumento de la producción de un 34\% en Filipinas, $11 \%$ en Sudáfrica, 9\% en Argentina y solamente un 5 y 6\% en EUA y España, respectivamente.

De manera consistente a través de los años, la característica de tolerancia a herbicidas (TH) es la de mayor utilización a nivel mundial. Durante el año 2010 se sembraron soya, maíz, canola, algodón, remolacha y alfalfa con esta característica, y el área sembrada alcanzó los 89,3 millones de hectáreas (James, 2010). Desde la entrada en producción de la soya transgénica Roundup Ready en 1996, introducida por la corporación Monsanto, se han obtenido nuevos organismos transgénicos resistentes al glifosato, en un intento por lograr una elevada productividad, bajos costos de producción, reducir la necesidad de labores y asegurar un fácil control de malezas a través del uso de herbicidas (Chhapekar, Raghavendrarao, Pavan, Ramakrishna, Singh, Phanindra, ...\& Kumar, 2015; Liu, Cao, Chen, Zhang, Ren, Lu, ... \& Wang, 2015)

En 2014, el 82\% (90,7 millones de hectáreas) de los 111 millones de hectáreas de soya plantadas en el mundo fueron transgénicas. Se plantaron 25,1 millones de hectáreas de algodón $\mathrm{Bt}$, lo que significa un $68 \%$ de los 37 millones de hectáreas globales de algodón. De los 184 millones de hectáreas totales de maíz plantadas en 2014, el 30\% (55,2 millones de hectáreas) fueron de maíz Bt. Finalmente, se sembraron 9 millones de hectáreas (25\%) de canola tolerante a herbicida (canola TH) de los 36 millones de hectáreas totales sembradas de esta especie, según lo muestra la Figura 3 tomada de James (2014).

Todo indica que las investigaciones para la obtención de plantas transgénicas seguirán creciendo, y la perspectiva a largo plazo es que los transgénicos sigan introduciéndose en la agricultura mundial, ocupando áreas mayores y sustituyendo parcial o totalmente a variedades tradicionales.

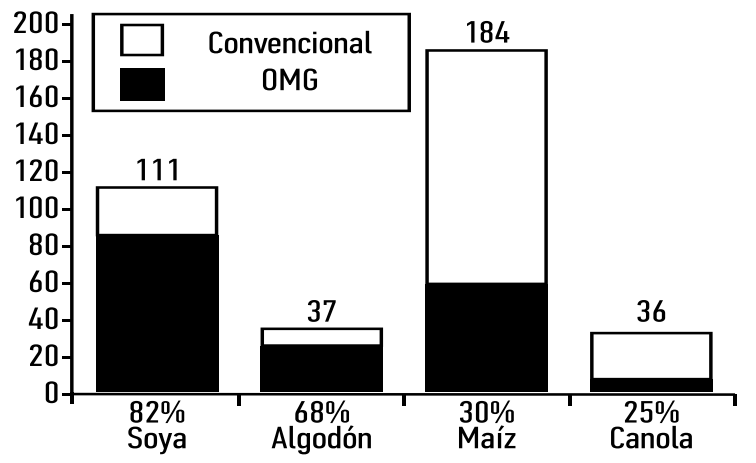

Figura 3. Proporción mundial (millones de hectáreas) entre las áreas sembradas con cultivos convencionales y organismos genéticamente modificados

IMPACTO SOCIAL DE LA BIOTECNOLOGÍA VEGETAL

No caben dudas acerca de que la biotecnología vegetal ha llegado a resultados sustanciales, capaces de transformar las concepciones y prácticas que hace medio siglo se manejaban en la agricultura. Como cualquier otra tecnología, ella ha generado un impacto social que puede medirse en diferentes aristas. Altieri (2003) en una extensa crítica a la biotecnología agrícola, dimensiona este análisis en cuatro vertientes:

- Sus propósitos (a qué necesidades responde, qué problemas se pretende solucionar, cómo afecta a la tecnología actual)

- Sus riesgos (ambiental, social, económico, político)

- Sus costos y beneficios (quién gana y quién pierde)

- Sus alternativas (si existen otras opciones diferentes a la biotecnología para mejorar la producción agrícola)

Altieri (2003) señala que aunque el fin declarado de la biotecnología vegetal es la reducción del hambre, el planeta genera suficientes alimentos para ello, y que el problema radica no en la producción, sino en la desigual distribución, y en la conversión de la producción alimentaria en agronegocios.

Uno de los elementos de riesgo que más preocupan es el efecto sobre la salud, el cual se ha especulado bastante. Hasta hace muy poco se podía decir, siguiendo a Wilches (2010), que se pueden adoptar posiciones favorables o desfavorables frente a la biotecnología, según las visiones optimistas o pesimistas de quienes hagan el análisis. Sin embargo, ya existen algunas investigaciones sobre los probables efectos de los productos transgénicos en la salud. En un estudio hecho por Carman, 
Vlieger, Ver Steeg, Sneller, Robinson, ClinchJones, ... \& Edwards (2013) sobre la influencia de los alimentos transgénicos, la autopsia de cerdos alimentados con una mezcla de soya y maíz transgénicos mostró inflamaciones de estómago 2,6 veces superiores a las de los cerdos que comieron soya y maíz convencionales. También, las hembras alimentadas con la mezcla de soya y maíz transgénicos tenían úteros significativamente mayores que las que comieron soya y maíz no transgénicos. Según los autores, esto podría estar asociado a diferentes tipos de patologías, varias de ellas malignas, y situación que merece estudios más detallados. Resultados similares fueron obtenidos por Brasil, Soares, Faria, Boaventura, Sampaio \& Ramos (2009) en ratas alimentadas con soya transgénica en cuanto a alteraciones del endometrio en las hembras. Un elemento muy alarmante es que los humanos y los cerdos tienen características anatómicas muy similares, en particular en el aparato digestivo, por lo que deberían realizarse estudios más profundos en humanos antes de seguir potenciando el consumo de alimentos transgénicos. Bøhn, Cuhra, Traavik, Sanden, Fagan \& Primicerio (2014) demostraron que en la soya Roundup Ready de la corporación Monsanto se acumulan altas concentraciones de glifosato y ácido aminometilfosfónico (AMPA, por sus siglas en inglés). Esto es resultado de las aplicaciones del herbicida glifosato, que no se hacen en la soya convencional ni en la soya orgánica, pues esta especie es susceptible a ese herbicida. Además, en la soya transgénica se encontraron niveles significativamente menores de proteína, y concentraciones significativamente superiores de ácidos grasos que propenden a la obesidad respecto a la soya convencional y la orgánica.

En 1980, el debate por la primera patente sobre un organismo vivo en los EE.UU se resolvió a favor de A. Chakrabarthi, que trabajando para la compañía General Electric obtuvo una bacteria genéticamente modificada, capaz de consumir crudo petrolífero en altas cantidades (Perelmuter, 2011). El veredicto abrió el camino a la posibilidad de patentar otros organismos, y con ello a la propiedad intelectual/ industrial sobre los organismos genéticamente modificados. Ello ha conducido a fenómenos aberrantes como que los agricultores que compran semilla transgénica no puedan venderla a terceros, o usar su cosecha como semilla en la próxima siembra. Con esto se crea una fuerte relación de dependencia económica. A la par de esto, se ha desarrollado la llamada "biopiratería" (Martínez-Castillo, 2009) por personas e institu- ciones de países desarrollados, que consiste en la prospección de recursos fitogenéticos en países subdesarrollados, con el objetivo de estudiar sus propiedades y patentarlos después. Por sólo citar un caso de biopiratería obsérvese el de la ayahuasca (Banisteriopsis caapi), patentada en 1986 por el norteamericano Loren Miller. La patente fue revocada en 1999 después de una protesta enérgica de chamanes del Amazonas, y le fue concedida nuevamente en 2001 hasta que expiró en 2003. Aunque este no es un caso de biotecnología, pues la planta no sufrió modificaciones genéticas en laboratorio (y esa fue una de las bases de la protesta) es un buen medidor para lo que está sucediendo en el presente y lo que se puede esperar en el futuro de la propiedad intelectual/industrial sobre los productos de la ingeniería genética.

Si bien los resultados de la biotecnología moderna son incuestionables en cuanto a la solución del problema científico que pretenden resolver, no es menos cierto que detrás de estos avances se mueve un poderoso interés de lucro. En 2008 (el panorama no ha cambiado) diez grandes empresas controlaban más del 30\% del comercio mundial de semillas, y cinco compañías (AstraZeneca, DuPont, Monsanto, Novartis y Aventis) tenían las riendas del $60 \%$ del comercio mundial de plaguicidas, más del $20 \%$ del mercado de semillas y prácticamente el $100 \%$ del comercio de semillas transgénicas (De la Torre, 2008). Bajo estas condiciones, es imposible coincidir con García-Gonzáles et al. (2010) cuando plantean que el acceso a la tecnología ya no es exclusivo de los países desarrollados, y que es necesario que todos reconozcan sus potencialidades y la exploten en todas sus dimensiones. No basta con querer hacerlo, es necesario poder hacerlo.

Como se ha visto, las principales críticas a la biotecnología se han dirigido hacia los propósitos, riesgos y beneficios de la introducción de los organismos genéticamente modificados en la agricultura. Otras biotecnologías más "blandas" a las que se ha hecho referencia en este artículo, no reciben los ataques de los que en este sentido es blande la ingeniería genética. Sin embargo, en general pueden incluirse en el grupo de tecnologías costosas, a las que no todos los países u organizaciones pueden acceder con facilidad. Por sólo tomar un ejemplo, aunque Dulloo, Ebert, Dussert, Gotor, Astorga, Vasquez, ... \& Snook (2009) señalan que la crioconservación de accesiones en cafeto -por su perpetuidad- cuesta menos que la conservación en bancos de germoplasma en el campo, según Conzález-Arnao \& Engelmann (2013) el costo de una accesión crioconservada in 
vitro en el Centro de Investigaciones de la papa en Perú es aproximadamente 300 USD por unidad. Este dato (que no incluye el costo de capacitación del personal especializado para el trabajo) demuestra que la aplicación de la biotecnología en la agricultura sigue siendo una posibilidad que no siempre está al alcance de todos.

CONCLUSIONES

Medio siglo después de que comenzara a aplicarse en la agricultura, la biotecnología vegetal ha demostrado que puede ofrecer resultados científicos útiles y múltiples aplicaciones prácticas. Otro panorama se refleja, en cambio, en cuanto a su impacto social en el que siguen observándose desigualdades en cuanto a la propiedad sobre los avances obtenidos y la apropiación de las ganancias que generan las prácticas biotecnológicas. La perspectiva es que se mantengan la acelerada introducción de los resultados de las investigaciones y la inequidad en la distribución de los beneficios.

\section{REFERENCIAS BIBLIOGRÁFICAS}

Adel Ahmed, A. S. \& Shaimaa Mohamed, M. (2010). Commercial production of tissue culture date palm (Phoenix dactylifera L.) by inflorescence technique. Journal of Genetic Engineering and Biotechnology, $8(2), 39-44$.

Altieri, M. (2003). Dimensiones éticas de la crítica agroecológica a la biotecnología agrícola, Acta Bioethica Año IX(1), 47-61.

Andrioli, A. L. (2013). Soja orgánica versus soja transgénica: um estudo sobre tecnologia e agricultura familiar na Região Fronteira Noroeste do Estado do Rio Grande do Sul. Rev. Contexto Educ, 23(80),195-222.

Asmah, N. H., Hasnida, N. H., Nashatul Zaimah, N. A., Noraliza, A. \& Nadiah Salmi, N. (2011). Synthetic seed technology for encapsulation and re growth of in vitro derived Acacia hybrid shoot and axillary buds. African J.

Biotechnol, 10(40), 7820-7824.

Aversano, R., Savarese, S., De Nova, J. M., Frusciante, L. \& Punzo, M. Carputo, D. (2009). Genetic stability at nuclear and plastid DNA level in regenerated plants of Solanum species and hybrids. Euphytica, 165, 353-361.

Barrows, J., Sexton, S. \& Zilberman, D. (2014). Agricultural Biotechnology: The promise and prospects of genetically modified crops. Journal of Economic Perspectives, 28(1), 99-120.

Bekheet, S. A. (2006). A synthetic seed method through encapsulation of in vitro proliferated bulblets of garlic (Allium sativum L.). Arab J. Biotech, 9, 415-426.

Biswas, A., Bari, M. A., Roy, M. \& Bhadra, S. K. (2011). In vitro propagation of Stemona tuberosa Lour.- A rare medicinal plant through high frequency shoot multiplication using nodal explants. Plant Tissue Cult. \& Biotech, 21(2), 151-159.

Bøhn, T., Cuhra, M., Traavik, T., Sanden, M., Fagan, J. \& Primicerio, R. (2014). Compositional differences in soybeans on the market: Clyphosate accumulates in Roundup Ready GM soybeans. Food Chemistry, 153, 207-215.

Brasil, F. B., Soares, L. L., Faria, T. S., Boaventura, G. T., Sampaio, F. J. B. \& Ramos, C. F. (2009). The impact of dietary organic and transgenic soy on the reproductive system of female adult rat. Anatomical Record, 292, 587-594.

Carman, J. A., Vlieger, H. R., Ver Steeg, L. J., Sneller, V. E., Robinson, G. W., Clinch-Jones, C. A., Haynes, J. I. \& Edwards, J. W. (2013). A long-term toxicology study on pigs fed a combined genetically modified (GM) soy and CM maize diet. Journal of Organic Systems, 8(1), 38-54.

Chhapekar, S., Raghavendrarao, S., Pavan, G., Ramakrishna, C., Singh, V. K., Phanindra, M. L. V., Dhandapani, G., Sreevathsa, R. \& Kumar, P. A. (2015). Transgenic rice expressing a codon-modified synthetic CP4-EPSPS confers tolerance to broadspectrum herbicide, glyphosate. Plant Cell Rep, 34, 721-731.

De la Torre, J. (2008). Aspectos éticos del uso de los organismos modificados genéticamente (OMG) en la agricultura y alimentación. ICADE, 73, 141-169.

Ducos, J. P., Terrier, B. \& Courtois, D. (2009). Disposable Bioreactors for Plant Micropropagation and Mass Plant Cell Culture. Adv. Biochem. Engin/Biotechnol, 115, 89-115.

Dulloo, M. E., Ebert, A. W. Dussert, S., Gotor, E., Astorga, C., Vasquez, N., Rakotomalala, J. J., Rabemiafara, A., Eira, M., Bellachew, B., Omondi, C., Engelmann, F., Anthony, F., Watts, J., Qamar, Z. \&Snook, L. (2009). Cost efficiency of cryopreservation as a long term conservation method for coffee genetic resources. Crop Science, 49, 2123-2138.

Engelmann, F. (2011). Use of biotechnologies for the conservation of plant biodiversity. In Vitro Cell. Dev. Biol.-Plant, 47, 5-16.

Estopá, M. (2005). El cultivo in vitro en la reproducción vegetativa en plantas de vivero. Horticultura Internacional, 1, 50-57.

García-Conzáles, R., Quiroz, K., Carrasco, B. \& Caligari, P. (2010). Plant tissue culture: Current status, opportunities and challenges. Ciencia e Investigación Agrari, 37(3), 5-30.

González-Arnao, M. T. \& Engelmann, F. (2013). Crioconservación de Plantas en América Latina y el Caribe. San José, Costa Rica: IICA.

Jain, S. M. (2001). Tissue culture-derived variation in crop improvement. Euphytica, 118, 153-166. 
James, C. (2010). Global Status of Commercialized Biotech/GM Crops: ISAAA Brief No. 42-210. Ithaca, New York: ISAAA.

James, C. (2014). Global Status of Commercialized Biotech/GM Crops: 2014. ISAAA Brief No. 49. Ithaca, New York: ISAAA.

Karim, R., Ahmed, F., Krishna Roy, U., Ara, T., Islam, R. \& Hossain, M. (2015). Varietal improvement of strawberry (Fragaria $\mathrm{x}$ ananassa Dutch.) through somaclonal variation using in vitro techniques. J. Agr. Sci. Tech, 17, 977-986.

Khorami, R. \& Safarnejad, A. (2011). In vitro selection of Foeniculum vulgare for salt tolerance. Not. Sci. Biol, 3(2), 90-97.

Koch, A. C., Ramgareeb, S., Stuart, R., Snyman, S. J. \& Watt, M. P. (2012). An in vitro mutagenesis protocol for the production of sugarcane tolerant to the herbicide Imazapyr. In Vitro Cell.Dev.Biol.-Plant, 48, 417-427.

Larkin, P. \& Scowcroft, W. (1981). Somaclonal variation-a novel source of variability from cell cultures for plant improvement. Theoret. Appl. Genet, 60, 197-214.

Liu, Y., Cao, G., Chen, R., Zhang, S., Ren, Y., Lu, W., Wang, J \& Wang, G. (2015). Transgenic tobacco simultaneously overexpressing glyphosate $\mathrm{N}$-acetyltransferase and 5-enolpyruvylshikimate3-phosphate synthase are more resistant to glyphosate than those containing one gene. Transgenic Res, 24, 753-763.

Mahmood, I., Razzaq, A., Rasheed, M., Qayyum, A. \& Ahmad, M. (2014). Employment of immature embryo culture for in vitro selection of drought tolerant somaclones of wheat. Bulg. J. Agric. Sci, 20(1), 155-161.

Martínez-Castillo, R. (2009). Biopiratería y pueblos indí genas: crítica y realidad. Revista Latioamericana de Derechos Humanos, 20(1), 27-38.

Miguel, C. \& Marum, L. (2011). An epigenetic view of plant cells cultured in vitro: somaclonal variation and beyond. J. Exp. Bot, 62(11), 3713-3725.

Noor, N. M., Kean, C. W., Vun, Y. L. \& MohammedHussein, Z. A. (2011). Invitro conservation of Malaysian biodiversity-achievements, challenges and future directions. In Vitro Cell. Dev. Biol.-Plant, 47, 26-36.

Paine, J. A., Shipton, C. A., Chaggar, S., Howells, R. M., Kennedy, M. J., Vernon, G., Wright, S. Y., Hinchliffe, E., Adams, J. L., Silverstone, A. L. \&Drake, R. (2005). Improving the nutritional value of Golden Rice through increased pro-vitamin A content. Nature Biotechnology, 23, 482-487.

Pence, V. C. (2011). Evaluating costs for the in vitro propagation and preservation of endangered plants. In Vitro Cell. Dev. Biol.-Plant, 47, 176-187.

Perelmuter, T. (2011). Bienes comunes vs. mercancías: las semillas en disputa. Un análisis sobre del rol de la propiedad intelectual en los actuales procesos de cercamientos. Sociedades Rurales, Producción y Medio Ambiente, 11(22), 53-86.

Pérez, J. (1998). Propagación y mejora genética de plantas por Biotecnología. Santa Clara, Cuba: Instituto de Biotecnología de las Plantas.

Priyadarsini, A., Sahoo, S. \& Rout, G. R. (2015). Study of in vitro selection and plant regeneration of Indica rice tolerant to iron. Int. J. Agric. Env. Biotechnol, 8(2), 285-293.

Qaim, M. (2009). The economics of genetically modified crops. Annual Review of Resource Economics, 1, 665-694.

Rahman, S., Biswas, N., Mehedi Hassan, M. Golam Ahmed, M., Mamun, A. N. K., Rafiqul Islam, M., Moniruzzaman, M. \& Enamul Haque, M. (2013). Micropropagation of banana (Musa sp.) cv. Agnishwar by in vitro shoot tip culture. Int. Res. J. Biotechnol, 4(4), 83-88.

Rao, N. K. (2004). Plant genetic resources: Advancing conservation and use through biotechnology. African Journal of Biotechnology, 3(2), 136-145.

Ribeiro, I. G. \& Marin, V. A. (2012). A falta de informacão sobre os Organismos Geneticamente Modificados no Brasil. Ciên. Saúde Colet, 17(2), 359-368.

Rugini, E., Gutierrez-Pesce, P., Silvestri, C., Lamancusa, S., Chiavaioli, G., Vittori, D. \& DePace, C. (2014). In vitro tissue culture for Helianthus tuberosus clonal selection to improve planting management and resistance to Sclerotinia infections. Ponencia presentada en Proceedings of the 58th Italian Society of Agricultural Genetics Annual Congress, Alghero, Italy.

Sarasan, V., Cripps, R., Ramsay, M. M., Atherton, C., McMichen, M., Prendergast, G. \& Rowntree, J. K. (2006). Conservation in vitro of threatened plants - progress in the past decade. In Vitro Cell. Dev. Biol.Plant, 42, 206-214.

Silva, D. \& Leite, L. (2013). Biotecnologia emelhoramento das variedades de vegetais: Cultivares e Transgénicos. Veredas do Direito: Direito Ambiente Desenvolv. Sust, 10, 19-23.

Valencia, L. D. C., Pascual, C. B. \& Delfin, E. F. (2014). In vitro selection of pineapple cv. "Queen" with resistance to culture filtrate of Phytophtora cinnamonis Rands. Phil. J. Crop Sci, 39(1), 58-86.

Vdovitchenko, Y. M. \& Kuzovkina, I. N. (2011). Artificial seeds as a way to produce ecologically clean herbal remedies and to preserve endangered plant species. Moscow Univ. Biolog. Sci. Bullet, 66(2), 48-50.

Weasel, L. H. (2008). Food Fray: Inside the Controversy over Genetically Modified Food. New York: AMACOM.

Wilches, A. M. (2010). La biotecnología en un mundo globalizado. Revista Colombiana de Bioética, 5(2), 164-169. 